


\title{
DESIGN AND TESTING OF ULTRALITE FABRIC REFLUX, TUBES
}

\author{
Keith A. Pauley, Zenen I. Antoniak, Loyd L. King, and Glenn W. Hollenberg \\ Pacific Northwest Laboratory \\ P.O. Box 999, MS: K6-47 \\ Richland, WA 99352.0999
}

(509) $\quad 376.5779$

\begin{abstract}
This paper describes the design, fabrication, and testing of Ultralite Fabric Reflux Tubes intended to provide thermal control for a Lunar Colony. The Ultralite Fabric Reflux Tubes, under this phase of development, are constructed of thin-walled copper liners overwrapped with aluminoborosilicate fabric. These devices were constructed and tested in air at the Pacific Northwest Laboratory and subsequently taken to the NASA Johnson Space Center for thermal vacuum experimentation.

\section{INTRODUCTION}

Ultralite Fabric Reflux Tubes (UFRTs) are being developed as the primary thermal management system for habitat waste heat rejection for the current lunar colony design. These devices would be deployed in a panel configuration and are intended to maintain personnel and equipment at a safe and optimal temperature. The investigation builds upon previous work conducted by the Pacific Northwest Laboratory for a variety of space thermal mangement requirements (Antoniak 1988, Antoniak 1989, Antoniak 1990, Pauley 1990, Webb 1990).
\end{abstract}

The waste heat from the lunar colony will be removed from the habitat and equipment areas at $294 \mathrm{~K}$ and transported to a heat pump. This heat pump will increase the working fluid temperature to $361 \mathrm{~K}$. The UFRT panel is thermally coupled to this working fluid and it radiates the waste heat to the space and lunar environs. The current habitat design requires the rejection of $150 \mathrm{~kW}$.

Four features separate the UFRT design from those of traditional reflux tube technologies: the thin metallic liner, ceramic fabric overbraid, water working fluid, and ceramic fabric evaporator wick structure. The thin metal liner, from 2.5 - $10 \mu \mathrm{m}$ thick, is used as the permeation barrier which maintains the fluid inside the tube. The thin metal liner is also used to transfer the stress associated with high internal pressures to the high strength ceramic fabric that provides the principal structure over the condenser region. The ceramic fabric used in this design is aluminoborosilicate, commercially known as Nextel ${ }^{7 M}$ by the $3 M$ Company. While this material has excellent tensile strength characteristics, $300-350 \mathrm{ksi}$ in this temperature range, its selection was based primarily on its selective absorptance and emittance characteristics in the solar spectrum. The fabric emittance has been measured as approximately 0.93 at $425 \mathrm{~K}$ while displaying an absorptance of only 0.10 in solar wavelengths. The high strength of the ceramic fabric/thin-walled liner combination has allowed the use of water, which is benign and a relatively good working fluid but displays relatively high pressures at the temperatures of interest for this application. In order to maintain advantageous mass considerations, the ceramic fabric material was also used as the circumferential wick in the evaporator. This wick is used to reduce the potential for reaching a critical heat flux in this area, which would produce local dryout and fail the reflux tube.

\section{FABRICATION ISSUES}

Fabrication issues for the initial UFRT design inciuded: i) pressiuie containment, 2) stress risers at the end-fittings, and 3) the fabric sizing. 
The design pressure for the lunar UFRT design was set at $690 \mathrm{kPa}$ which corresponded to $2 / 3$ of the yield stress of the evaporator wall, which had been determined by both analysis and experiment to be the area of lowest strength. In order to demonstrate the capability of the devices, the tubes were over-pressurized to $1720 \mathrm{kPa}$ at $294 \mathrm{~K}$. Each tube was qualified under these conditions. Maximum burst tests were conducted under this configuration, which yielded a maximum load of $4200 \mathrm{kPa}$ at failure.

Early prototype UFRT designs displaved a stress riser failure mode at the end fittings. The fabric was attached to the thickened portion of the end-fitting at an abrupt angle. Upon pressurization, this region produced high stress concentrations which first failed the fabric then the liner. This issue was resolved by slightly tapering the transition from thin-walled liner to the end-fitting.

The ceramic fabrics used in the current designs were Nextel 312 and silicon carbide. The Nextel is coated with organic sizing, which permits handling without damage to either the fabric or personnel. The sizing may be removed by heat cleaning at about $800 \mathrm{~K}$. However, if not removed prior to the operation of a UFRT, discoloration can be seen in the fabric due to partial volatilization of the organic resin. The Nextel wick was heat treated at a higher temperature (about $1200 \mathrm{~K}$ ), not only to remove the sizing but also to alter its crystal structure for longterm compatibility with water. The Nextel overwrap was not heat cleaned in the current design, but will be both heat cleaned and heat treated in future UFRT designs.

Figure 1 traces the fabrication of a silicon carbide UFRT. From left is right, a copper preform is processed through the Uniscan device, developed by PNL, which takes a $20 \mathrm{~cm}$ feedstock with a wall thickness of $300 \mu \mathrm{m}$ and produces a norninal $1 \mathrm{~m}$ liner with $50 \mu \mathrm{m}$ walls and integral thickened end regions. The silicon carbide is then attached to the end regions with compression fittings, the Nextel wick is placed in the evaporator, and finally the end caps are brazed into place. A $2.3 \mathrm{kPa}$ check valve is placed on the end port, in order to contain an argon cover gas and prevent the collapse of the tube. This produces a UFRT with a mass of less than $140 \mathrm{~g}$.

\section{AMBIENT ATMOSPHERIC TESTS}

To date, several $\mathrm{SiC}$ and Nextel-covered reflux tubes have been successfully tested in ambient air. The purpose of these tests was to observe and ensure proper startup behavior, and to test maximum power capability. Test equipment consisted of electrical heaters clamped onto the evaporator, thermocouples, a pressure transducer, and an infrared camera. The camera allowed the verification of isothermal operation and measurement of the fabric surface temperature based on the emittance previously measured at slightly higher temperatures.

Figure 2 illustrates the results of the most current experimental work. The evaporator and condenser temperatures, as well as the pressure of the working fluid, track the power input well over this power range. The data also illustrate the ability of the reflux tube to adequately perform over several power levels up to $200 \mathrm{~W}$. However, this power level does not seem to be a maximum and further testing is necessary to define the design limits of this device.

\section{THERMAL VACUUM TESTS}

Thermal vacuum testing of three UFRTs was conducted at facilities located at the NASA Johnson Space Center. An array of UFRTs was tested in a thermal vacuum chamber in order to map their individual performance characteristics over a variety of conditions. The test matrix, shown in Table 1, included startup and shutdown, frozen startup, load/follow transients, lunar day and night performance, and maximum heat rejection capabilities. 


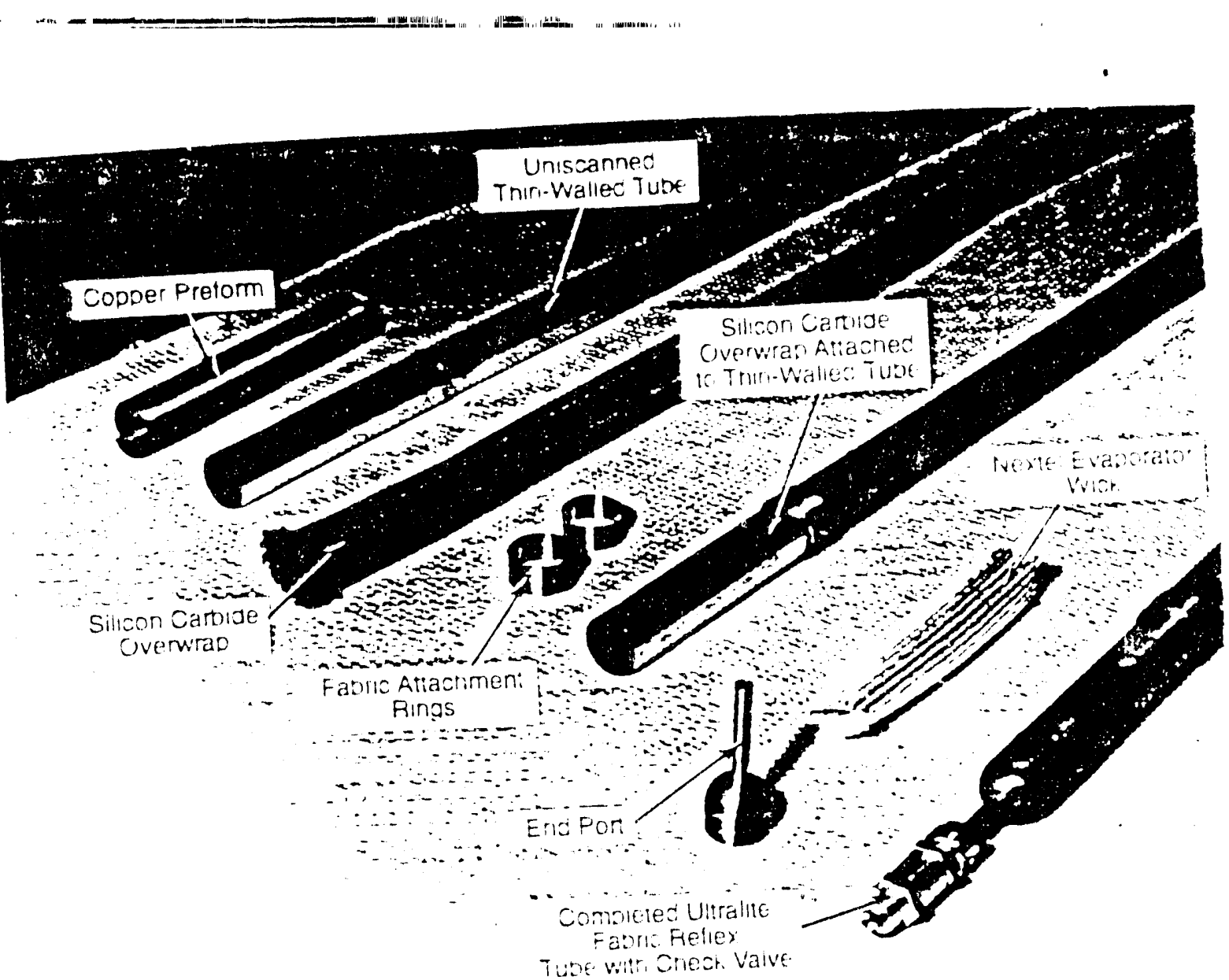

FIGURE 1. Stages of Fabrication of a Silicon Carbide Ultrallte Fabric Reflux Tube.

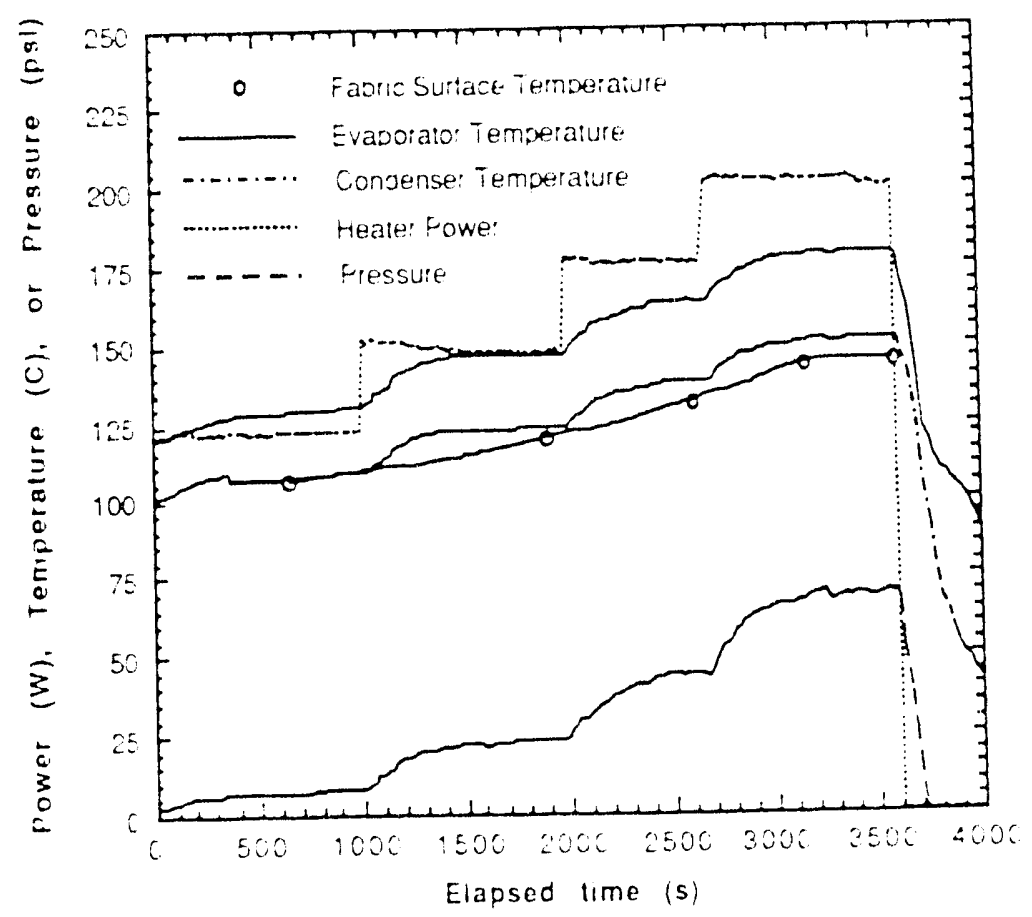

FIGUFE 2. Ambient Laboratory Tesi Fiesults of the Current Uliralle Fabric Reflux Tude Design. 
TABLE 1. Thermal Vacuum Test Matrix

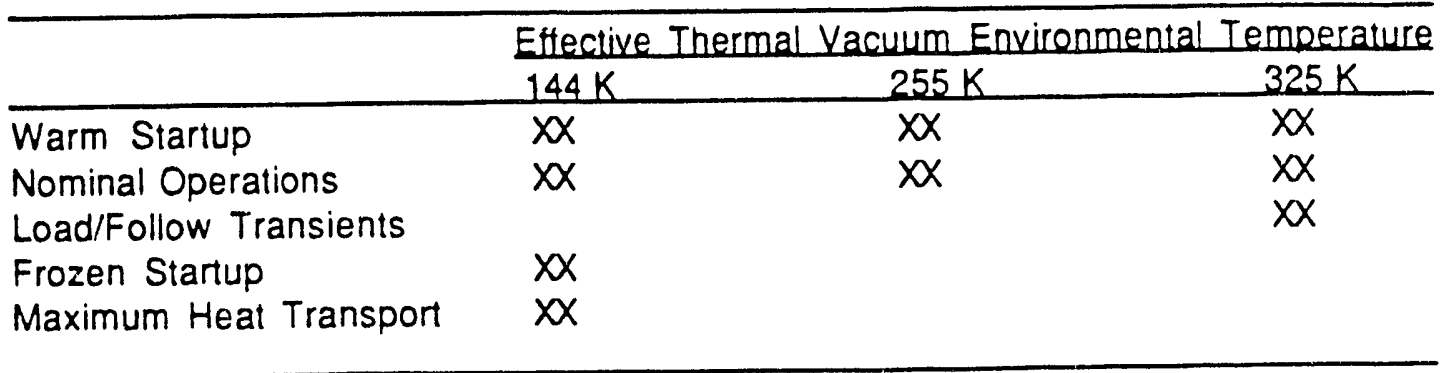

The UFRT test assembly, shown in Figure 3, was configured in Chamber $E$ in Building 33 at the NASA Johnson Space Center. Five UFRTs were originally placed inside the chamber in a mounting bracket, shown in Figures 4 and 5. However, two UFRTs were failed during setup and testing was limited to the reinaining three. The evaporator end of the reflux tubes, shown in Figure 5, was wrapped with a glass heater rope and covered with a copper thermal shroud for even distribution of heat input along the evaporator length. The chamber thermal shroud temperature was held constant by the flow of liquid nitrogen at $115 \mathrm{~K}$ while infrared lamps were used to adjust the effective environmental temperature. The UFRTs were tested at environmental temperatures of $325 \mathrm{~K}, 255 \mathrm{~K}$, and $144 \mathrm{~K}$.

The thermal vacuum chamber was evacuated and maintained at approximately $10.4 \mathrm{kPa}$. During the chamber pump down the UFRTs were plumbed to be open to the chamber environment. When the chamber was stabilized at a steady state pressure, the UFRTs were valved closed to the chamber. The UFRTs were filled with the water working fluid by using an array of charging tubes, external to the thermal vacuum chamber. These charging tubes were hard-packed with water and heated with a heat gun. In order to initiate the fill procedure, external valves were opened to allow transport of the working fluid through the fill lines into

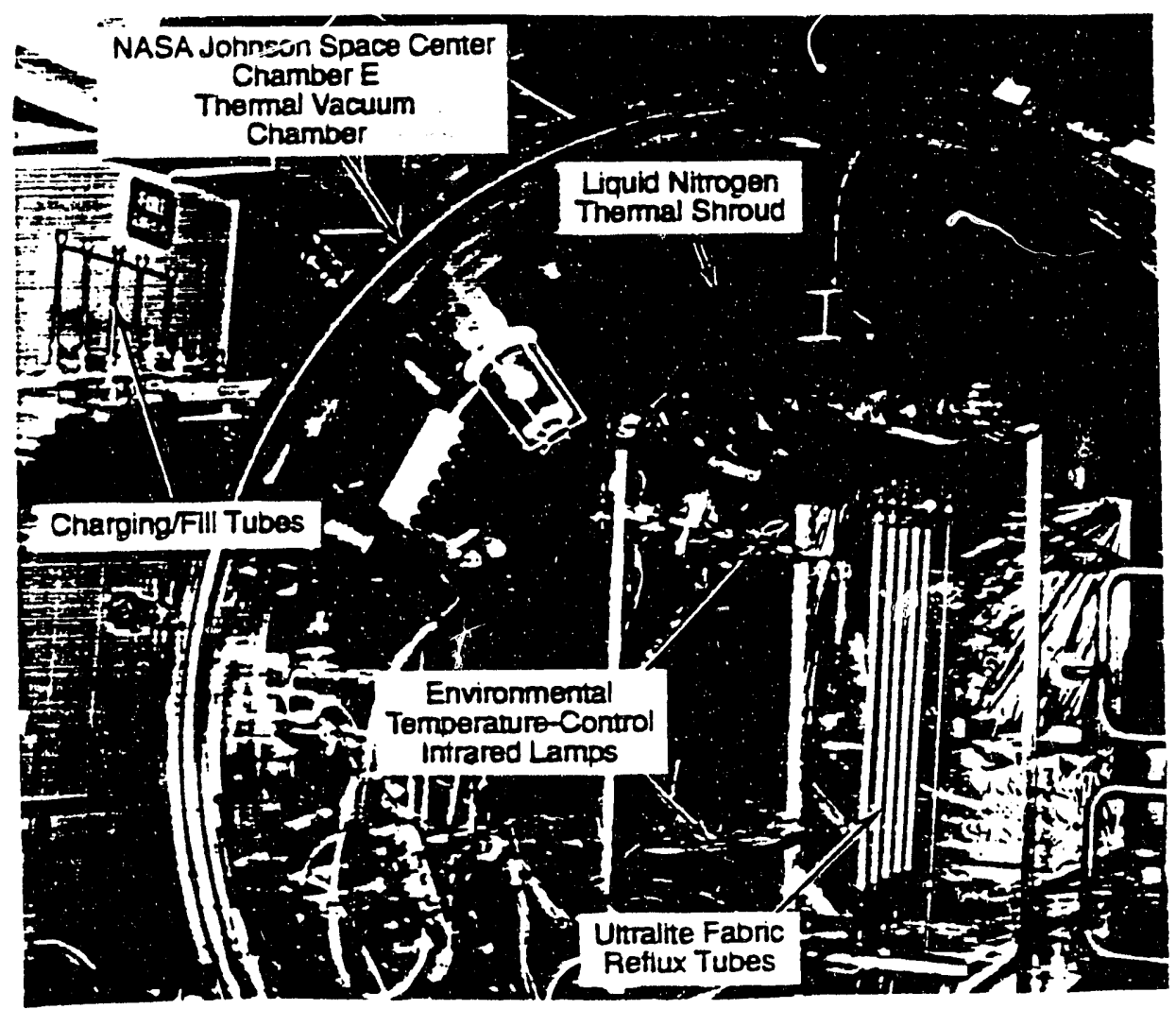

FIGURE 3. UFRT Tes! Configuration in Chamber E at NASA Johnson Space Center. 


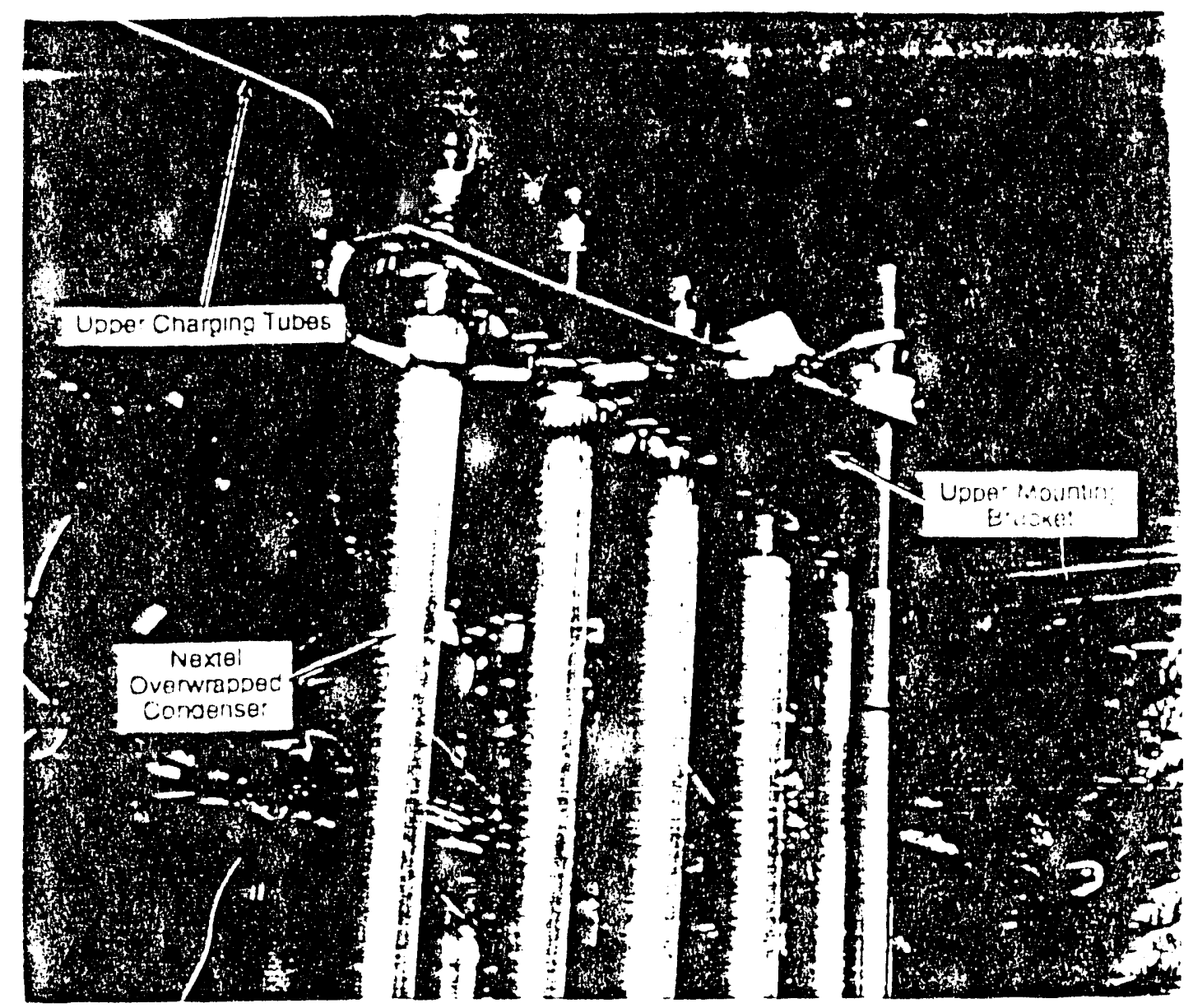

FIGURE 4. Upper Feoron of the U:=RT TeSi Assembly

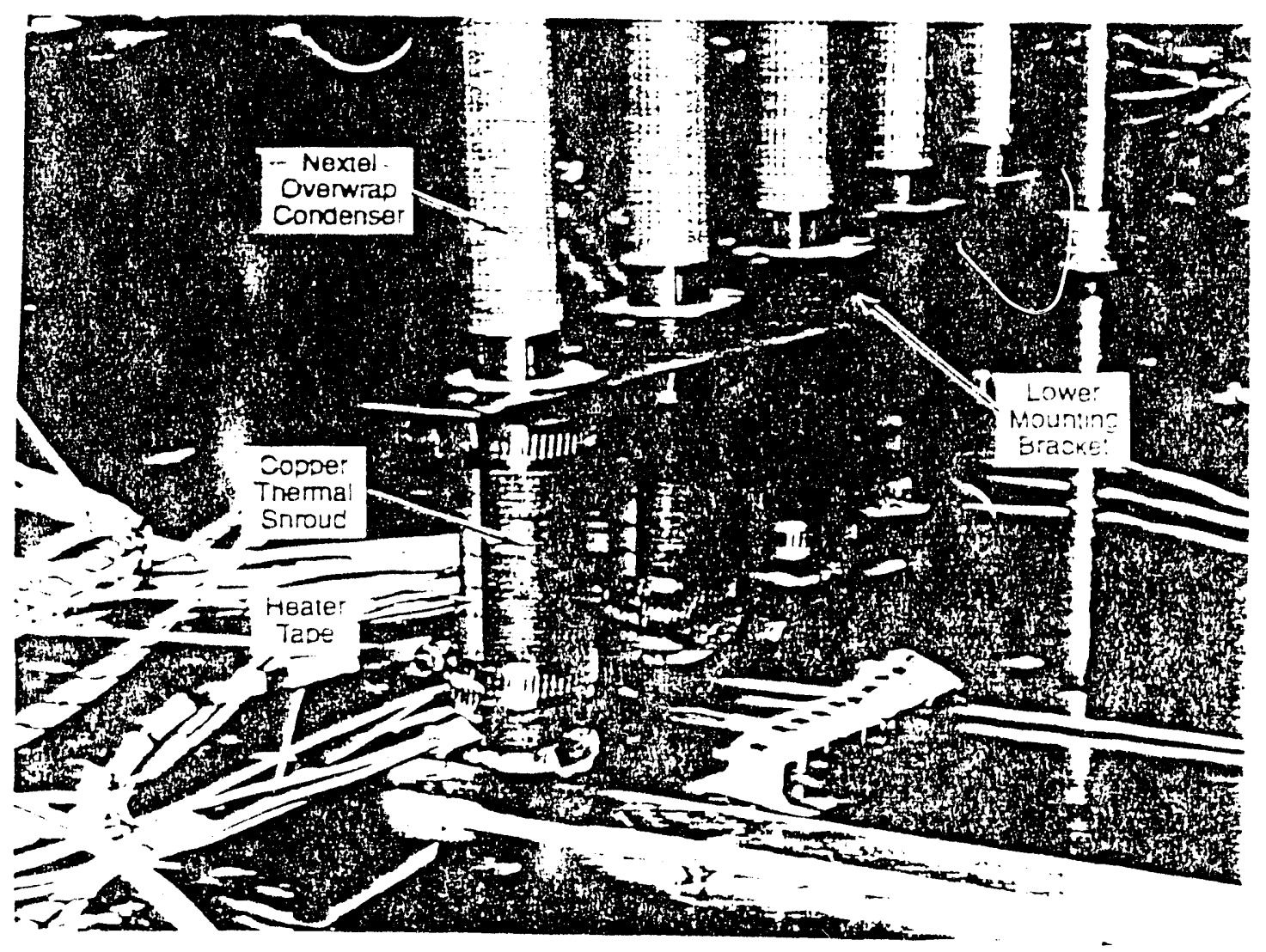

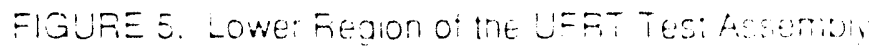


each UFRT. This charging procedure was accomplished separately for each UFRT test anticle. Upon completion of the fill procedure, each UFRT was isolated by closing the external valves on the fill lines.

The thermal vacuum tests were conducted and successfully demonstrated the capabilities of the UFRT design to perform over a variety of conditions. Several results were confirmed by these tests:

- The performance of the UFRT design was limited by the surface area available to radiate the heat from the condenser region. The design was not limited by evaporator heat flux, condensate return flow, entrainment, or sonic flow.

- The condenser region of the UFRT design was isothermal over the exterior length. The design operated a saturated internal conditions and did not display appreciable anomalies in conductive contact resistance between the ceramic tabric overwrap and copper thin-walled inner liner.

- The ability of the UFRT design to respond to load/follow transients was masked by the time constant of the heat elements used in the tests. However, the design followed the actual heat input adequately and each reflux tube temperature trended well with power.

- The UFRT design responded adequately to an instantaneous addition of full power from a fully frozen condition, as shown in Figure 6 . This condition did not stress the capabilities of the design.

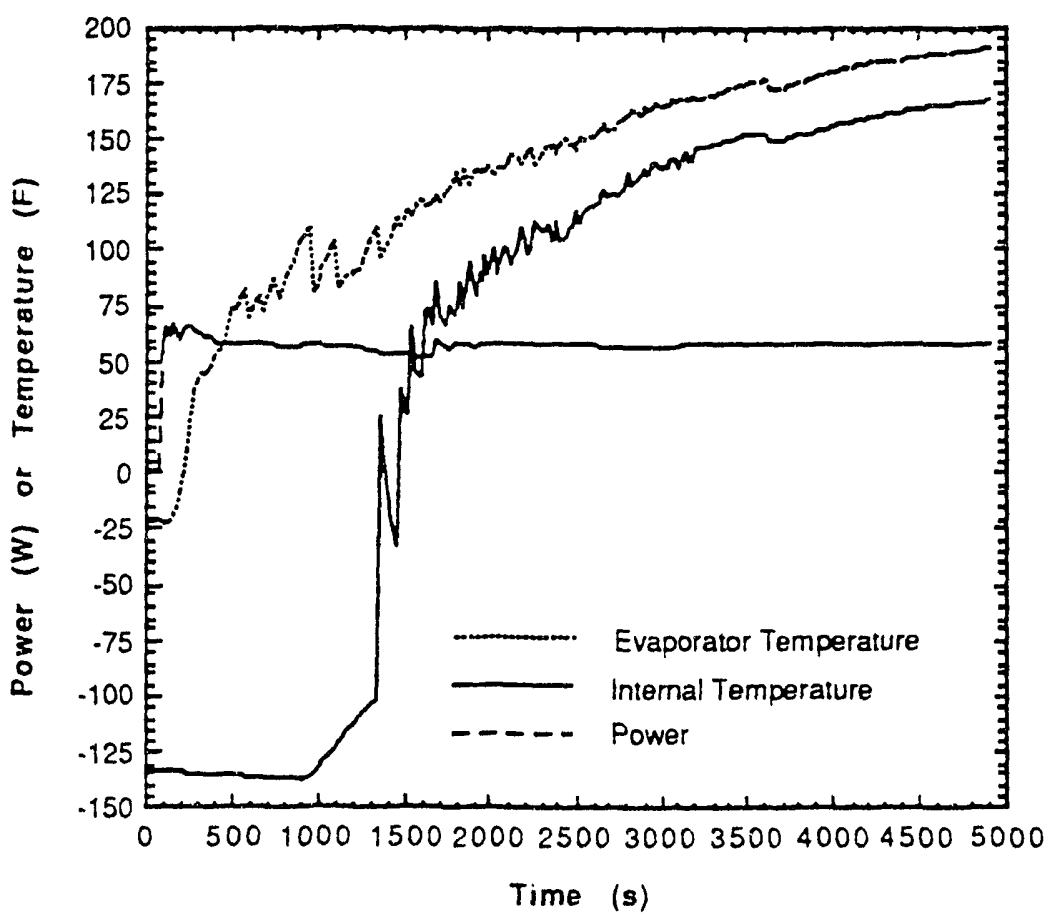

FIGURE 6. Frozen Startup Test Results of the Current Ultralite Fabric Reflux Tube Design. 
- Maximum heat rejection capabilities were not demonstrated due to the failure of several instruments, including the heating elements, at $90 \mathrm{~W}$ and an environmental temperature of $144 \mathrm{~K}$. Since this was the last test series, the experiment was terminated without defining the transport limits of the UFRT design.

\section{CONCLUSION}

Ultralite Fabric/Cu reflux tubes have been constructed and tested with a water working fluid in both ambient laboratory and thermal vacuum environments. The construction of the UFRT design presented challenges to contain the pressure of the working fluid at the operational temperature, reduce stress risers at the end-fitting transitions, and degradation of the optical properties due to the fabric sizing. The performance of this design has met all expectations. Startup has been accomplished with no flaws and performance limits have been tested to $200 \mathrm{~W}$ and an internal pressure of about $500 \mathrm{kPa}$ at ambient atmospheric conditions. Thermal vacuum tests have indicated that the UFRT design operates isothermally along the condenser region and performs as anticipated in nominal operation and load following. The UFRT design also began operations without incident from a full frozen initial condition. Due to instrumentation failures, the design was only tested to $90 \mathrm{~W}$ in a thermal vacuum environment. Although these UFRTs represent non-optimized test articles, they have a mass (based on projected, one-sided condenser area) of less than $6 \mathrm{~kg} / \mathrm{m}^{2}$. The potential exists for significantly reducing this mass with refinement of the existing design and possibly even further through the addition of fins.

\section{Acknowledgements}

Support for this work from the NASA Johnson Space Center through DE-ACO6-76RLO 1830 is gratefully acknowledged.

\section{References}

Antoniak, Z. I. et al. 1988. Fabric Space Radiators. PNL-6458. Pacific Northwest Laboratory, Richland, Washington.

Antoniak, Z. I. et al. 1989. "Construction and Testing of Ceramic Fabric Radiator Heat Pipe Components for Space Nuclear Power". Proceedings of the Sixth Symposium on Space Nuclear Power Systems. Institute for Space Nuclear Power Studies, University of New Mexico, Albuquerque, New Mexico.

Antoniak, Z. I. et al. 1990. "Construction and Testing of Advanced Ceramic Fabric Radiator Components to $1000 \mathrm{K"}$. Proceedinos of the Seventh Sympesium on Space Nuclear Power Systems. Institute for Space Nuclear Power Studies, University of New Mexico, Albuquerque, New Mexico.

Pauley, K. A. et al. 1990. "Design Considerations for a Ceramic Fabric Radiator". Engineerina. construction and Operations in Space: Proceedings of Space 90 . American Society of Civil Engineers, New York, New York.

Webb, B. J. et al. 1990. "Advanced Ceramic Fabric Body Mounted Radiator for Space Station Freedom Phase O Design". Proceedinos of the fIAAAASME Sixth Thermophysics and Heat Iransfer Cenference. American Society of Mechanical Engineers, New York, New York. 

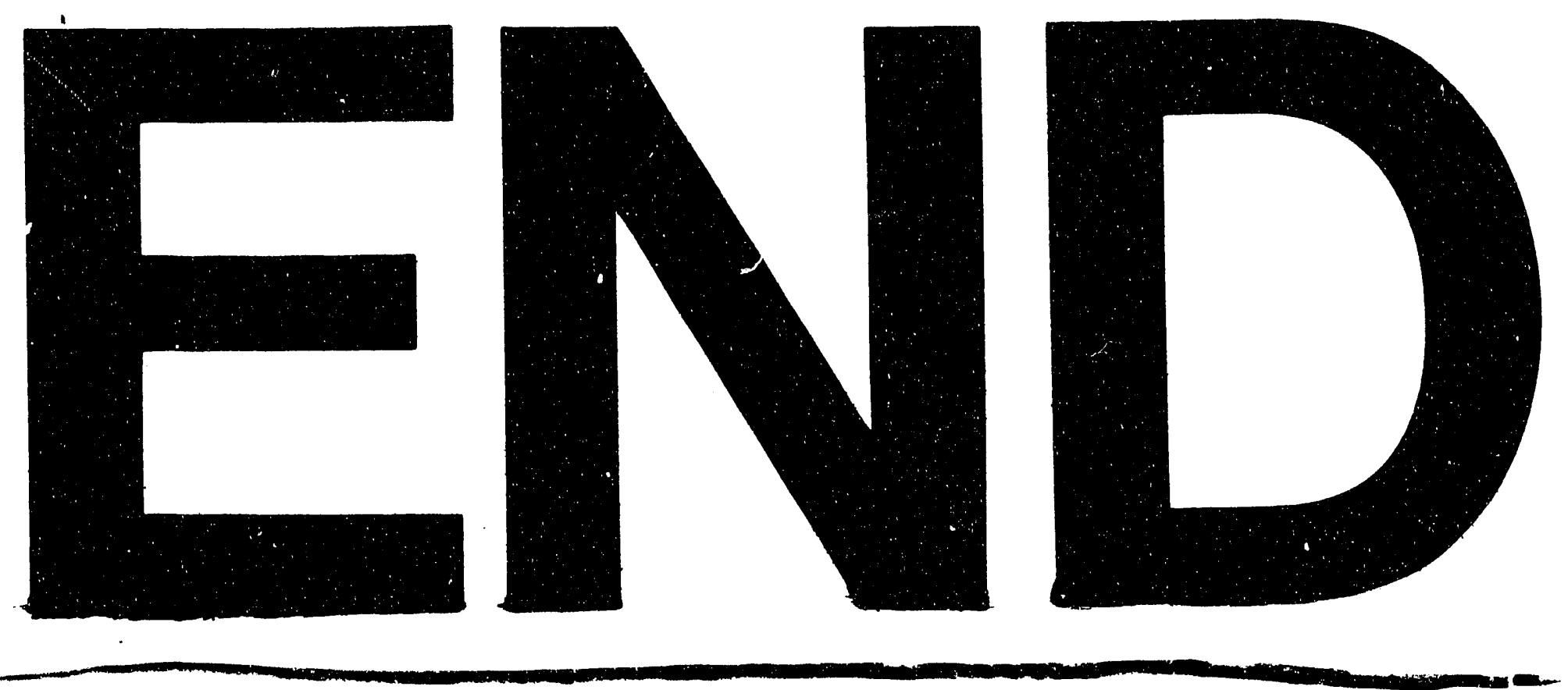

1
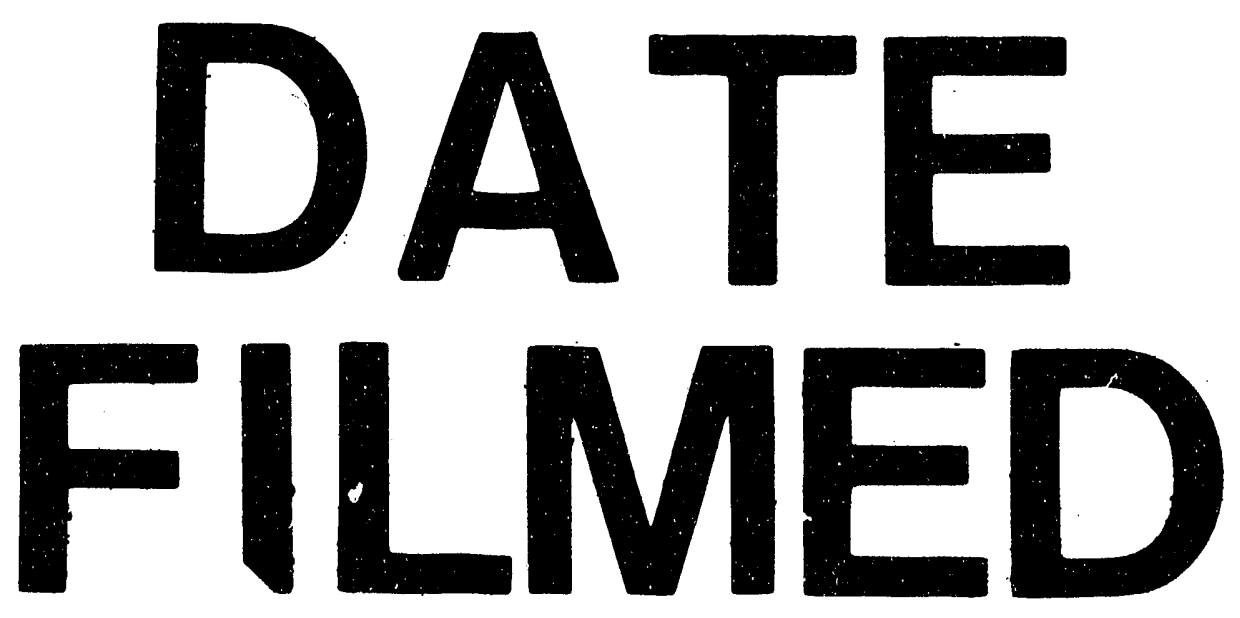

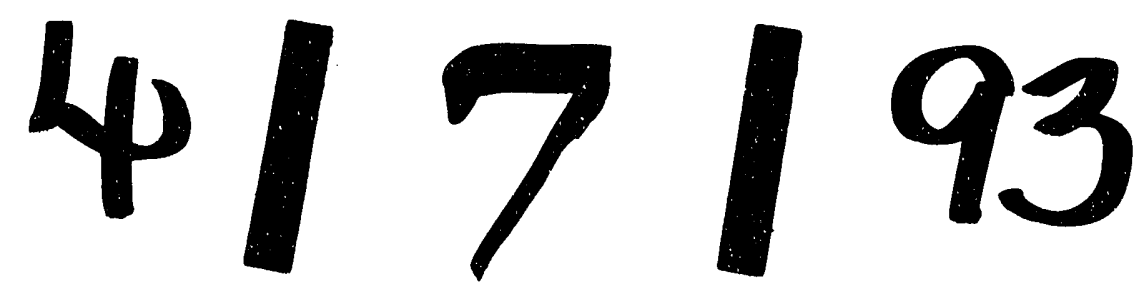


